Scientific Electronic Archives

Issue ID: Sci. Elec. Arch. Vol. 15 (1)

January 2022

DOI: http://dx.doi.org/10.36560/15120221505

Article link: https://sea.ufr.edu.br/SEA/article/view/1505

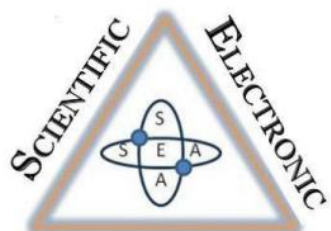

ArChIves

ISSN 2316-9281

\title{
Esterco caprino na composição de substratos para germinação e emergência de Lablab purpureus
}

\section{Goat manure in the composition of substrates for germination and emergency of Lablab purpureus}

\author{
Corresponding author \\ Esmeraldo Dias da Silva \\ Universidade do Estado da Bahia \\ esmeraldoagro@gmail.com
}

Hugo Renato da Rocha Matos

Universidade do Estado da Bahia

Bruno Gabriel Amorim Barros

Universidade do Estado da Bahia

Flávio José Vieira de Oliveira

Universidade do Estado da Bahia

\begin{abstract}
Resumo. Objetivou-se avaliar a germinação, emergência e o desenvolvimento inicial do feijão Lablab purpureus, em função do efeito proporções de esterco caprino misturadas com outras fontes de substratos na produção de mudas. A pesquisa foi realizada no Departamento de Tecnologia e Ciências Sociais da Universidade do Estado da Bahia. O experimento foi conduzido em casa de vegetação, sendo os tratamentos: T1: esterco caprino curtido; T2: esterco caprino curtido + pó de serra; T3: esterco caprino curtido + substrato comercial; T4: esterco caprino curtido + areia lavada. Foi avaliada a emergência, através do seu índice de velocidade, porcentagem de emergência e ao final do experimento foram analisadas altura da planta, comprimento da raiz, diâmetro do colmo, número de folhas, massa fresca e seca da planta. Constatou-se que o tratamento esterco caprino + substrato comercial obteve-se melhor desempenho no crescimento inicial do feijoeiro.
\end{abstract}

Palavras-chaves: Feijão, plântulas, semiárido, mudas.

Abstract. The aim of this study was to evaluate the germination, emergence and initial development of Lablab purpureus bean, as a function of the effect of proportions of goat manure mixed with other sources of substrates in the production of seedlings. The research was carried out at the Department of Technology and Social Sciences at the State University of Bahia. The experiment was conducted in a greenhouse, with the treatments: T1: tanned goat manure; T2: tanned goat manure + saw dust; T3: tanned goat manure + commercial substrate; T4: tanned goat manure + washed sand. The emergence was evaluated through its velocity index, percentage of emergence and at the end of the experiment, plant height, root length, stem diameter, number of leaves, fresh and dry weight of the plant were analyzed. It was found that the treatment of goat manure + commercial substrate had better performance in the initial growth of common bean.

Keywords: Beans, seedlings, semiarid, seedlings.

\section{Introdução}

O feijão Lablab cujo nome cientifico é Lablab purpureus, conhecido anteriormente por Dolichos lablab, é pertencente à família Fabaceae, sendo uma leguminosa herbácea, anual a bianual. É uma espécie que cresce nas regiões tropicais e subtropicais do mundo (ENGLE et al., 2000). Tem sua origem na Índia, e posteriormente foram introduzidas nos continentes Africano e Asiático durante o século VIII (MURPHY E COLUCCI, 1999). O Lablab é uma planta que possui múltiplos usos, com capacidade de ser um recurso extraordinário tanto para a produção agrícola, alimentação humana e animal (PENGELY E LISSON, 2002), 
além de suas propriedades biofuncionais para uso farmacêutico (MORRIS, 2009). Na produção de biomassa, possui alta produção, chegando a produzir entre 4 e 10 toneladas de matéria seca/ha, dependendo das variáveis: solo, clima, competição com ervas espontâneas e a variedade do grão (FRANCO et al. 2006).

Segundo Franco et al. (2006) afirma que o feijão Lablab tem potencial na fertilização de solos, chegando a substituir a aplicação de 40 a $80 \mathrm{~kg} / \mathrm{ha}$ de nitrogênio, pode ser usado para a recuperação da fertilidade do solo. Quando usado como alimento humano, é consumido na forma de vagens verdes ou sementes maduras e as folhas como legumes.

Para se definir o vigor de uma planta é levado em consideração dois parâmetros, emergência e acumulo de massa seca de plântulas; e esses fatores são afetados diretamente pelo substrato utilizado, assim, é de suma importância que as condições químicas e físicas do substrato estejam adequados para a produção de mudas vigorosas (PEREIRA et al., 2012). O substrato é o suporte físico da planta e além disso, supri suas necessidades fornecendo nutrientes e água. Vale et al. (2004) também ressaltam o papel fundamental do substrato na produção de mudas de qualidade, possuindo influência direta na arquitetura do sistema radicular e no estado nutricional das plantas.

A qualidade do substrato está relacionado com a presença de características como a ausência de patógenos, riqueza em nutrientes essenciais, textura, estrutura e pH adequados, além de fácil aquisição e transporte, retenção de água, porosidade, água disponível, salinidade e teor de matéria orgânica (SILVA et al., 2001; SMIDERLE E MINAMI, 2001; SCHMITZ et al. 2002). Fermino e Kampf (2003) citam que o uso de substratos orgânicos com as propriedades necessárias a planta cultivada, traz benefícios de redução do tempo de cultivo, diminuição no consumo de fertilizantes químicos, agrotóxicos e mão-de-obra.

$\mathrm{Na}$ produção de substratos existe uma grande dificuldade para se encontrar materiais puros que tenham características ideais para prover as plantas o que elas precisam para o seu desenvolvimento, e a esses substratos são adicionados outros materiais ou produtos, melhorando suas características e funcionando como condicionadores (SANTOS et al. 2000). É comumente utilizado misturas de matéria orgânica e diferentes tipos de solos como substrato no processo de desenvolvimento de mudas, isso devido aos benefícios que são agregados as propriedades físico-químicas do solo (ARAÚJO $E$ SOBRINHO, 2011).

O uso de matéria orgânica na produção de mudas tem mostrado diversos resultados positivos, e esses resultados variam com a fonte utilizada (FREIRE et al., 2015).

$\mathrm{Na}$ formulação de misturas para substratos é muito comum o uso de matéria orgânica de origem animal e de diferentes tipos de animais.
Melo et al. (2015) ressaltam que doses de adubos orgânico de origem animal, como o de origem caprina, apresenta benefícios, principalmente, melhorias na produtividade de biomassa das plantas, ocasionando redução dos custos de produção.

$\mathrm{Na}$ região do semiárido nordestino, os solos apresentam déficit em nutrientes, principalmente $\mathrm{N}$ e $\mathrm{P}$, limitando a produção vegetal. Para a região, o uso de esterco caprino é uma alternativa para os produtores, devido a presença de $\mathrm{N}$ e $\mathrm{P}$ na sua composição, visto que, se utilizado suprirá os solos da região com esses elementos (SILVA et al., 2007).

O presente trabalho teve como objetivo avaliar a germinação, emergência e desenvolvimento inicial do feijão Lablab purpureus, verificando a influência de esterco caprino misturado com outros materiais para composição de um substrato.

\section{Material e métodos}

O trabalho foi realizado na área experimental do Departamento de Tecnologia e Ciências Sociais (DTCS), Campus III, da Universidade do Estado da Bahia, no período de 20 de dezembro 2019 a 20 de janeiro de 2020. Antes do início do experimento foi levada uma amostra de cada tratamento para realização de análises químicas em laboratório especializado (Tabela 1).

As sementes do feijão Lablab antes de serem semeadas passaram por um processo de quebra de dormência, passando por escarificação manual lixadas na região oposta ao hilo, e em seguida imersas em água durante o período de 1 hora.

Após a quebra de dormência as sementes foram semeadas em tubetes com diferentes substratos, sendo divididos em 4 tratamentos com diferentes misturas. O primeiro tratamento (T1) foi constituído por esterco caprino curtido; já o segundo (T2) foi a mistura esterco caprino curtido + areia lavada; O (T3): esterco caprino curtido + substrato comercial e por último o (T4): esterco caprino curtido + pó de serra. Todos os tratamentos onde tiveram mistura obedeceram a relação 1:1.

O delineamento experimental utilizado foi inteiramente casualizado, contendo 25 repetições totalizando em 100 unidades amostrais. A contagem do número plântulas emergidas foi avaliada diariamente, sempre no mesmo horário, pela manhã, adotou-se como critério para a avaliação da emergência das plântulas 0 aparecimento das estruturas primárias sobre o substrato.

As características avaliadas foram: Índice de velocidade de emergência (IVE), porcentagem de emergência de plântulas (\%E), comprimento das raízes (CR) e da parte aérea das plântulas (CPA), Número de folhas (NF), Diâmetro do colmo (DC), Massa seca (MS) e fresca das plântulas (MF).

Aos trigésimo dia após a semeadura, as mudas foram retiradas dos tubetes e lavadas para a 
remoção do substrato agregado as raízes. Sendo realizadas as seguintes avaliações: CR, CPA.

A raiz principal e a parte aérea das plântulas de cada repetição foram medidas com o auxílio de uma régua graduada em centímetros, sendo os resultados expressos em centímetro por plântula. Para medir a altura da muda foi considerado a distância a partir do nível do substrato até a folha mais alta, e o da raiz, foi considerado o comprimento da maior raiz do sistema radicular.

Para determinar o número de folhas realizou-se a contagem das folhas de cada plântula, de cada repetição, por tratamento. Para a determinação do DC, foi utilizado um paquímetro digital, medida feita acima do nível do substrato.

Ao final do trigésimo dia após a semeadura as plântulas foram pesadas em uma balança analítica, e posteriormente submetidas à secagem, em estufa de circulação forçada à temperatura de $65 \pm 5^{\circ} \mathrm{C}$, durante o período de 72 horas, para a determinação da MS e MF.

Os dados obtidos foram submetidos ao programa estatístico SISVAR, com o teste de Tukey a 5\% de probabilidade.

\section{Resultados e discussão}

Os tratamentos esterco caprino (T1), esterco caprino + pó de serra (T2) e esterco caprino + substrato comercial (T3) iniciaram as suas emergências ao terceiro dia após a semeadura. Já o esterco caprino + areia lavada (T4) iniciou ao quarto dia.

Para o índice de velocidade de emergência, os tratamentos T2 e T3 apresentaram resultados superiores em relação aos demais, com valores 1,40 e 1,46, respectivamente (Tabela 2).

A maior velocidade de emergência ajuda no desenvolvimento da plântula, onde os processos pré-germinativos auxiliam na rápida emergência das espécies (DUTRA et al., 2012). Segundo Dan et al. (2010) e Sousa et al. (2015), a velocidade de germinação é um fator importante para um rápido estabelecimento das plântulas em condições de campo. Quanto maior for o IVE de uma espécie, maior será o seu desempenho para o crescimento e desenvolvimento da mesma, além da maior resistência a estresses que possam surgir $e$ atrapalhar no processo de desenvolvimento da planta (SOUSA et al., 2015).

Santos e Campos (2009) no seu estudo observa que para o fator emergência de plântulas de Tabebuia ochracea (Chamb.) Standl., o pó de serra curtido em mistura com substrato comercial mostrou-se igualmente favorável. Já Scalon et al. (2003) observaram que o substrato areia não é o mais adequado para a germinação de sementes de Caesalpinia pelthophoroides Benth. Resultado semelhante foi observado por Lima e Dornelles (2002) em estudo com três espécies de Annona ( $A$. crassiflora Mart., A. squamosa L. e A. muricata L.), o substrato areia resultou nos menores percentuais de germinação.
Os tratamentos T2 e T3 foram observados a presença de uma maior retenção de água. Em estudo com diferentes tipos de solos e em casa de vegetação telada na germinação de Tabebuia heptaphylla, Bocchese et al. (2008) ressalta que solos com melhor retenção de água, relacionados à maior área superficial das partículas e maior capacidade de troca catiônica, como solos com presença de argila e matéria orgânica, favoreceram a germinação da espécie.

Com relação a porcentagem de emergência, o T3 obteve o melhor resultado com $46 \%$, seguido do T4 com 44\%, T2 com $42 \%$ e T1 com 38\%. Gazola et al. (2013) avaliando o efeito de substratos comerciais na emergência e crescimento inicial de plântulas de pepino, observaram que as maiores médias de porcentagens de emergência e índices de velocidade de emergência, foram encontrados no substrato fort condicionador. Gondin et al. (2015) e Alves et al. (2015) afirmam que a característica de retenção de água de um substrato favorece a germinação e emergência das plântulas de Paricá.

O tratamento com esterco caprino (T1) apresentou uma camada superficial dura que dificultou a infiltração da água no substrato. Piton (2016) em um trabalho realizado com diferentes substratos observou que o substrato solo de Cerrado + esterco bovino, houve a formação de uma camada superficial fina, dura, seca e impermeável, dificultando a infiltração da água e impossibilitando às plântulas emergirem.

Já para o índice de comprimento da raiz principal o tratamento esterco caprino + substrato comercial obteve o melhor resultado com relação aos demais tratamentos. Os T1, T4 e T2, tiveram os menores valores, não apresentando diferença estatística entre si (Tabela 3).

Bardiviesso et al. (2011) afirmam que o elemento cálcio proporciona um maior desenvolvimento do sistema radicular. Malavolta et al. (1996) citam a importância do elemento fósforo nas plantas, esse elemento está presente nas moléculas de DNA, RNA, nos polímeros de nucleotídios, ésteres e no fósforo inorgânico, além de estar relacionado ao desenvolvimento radicular. Em trabalho realizado com diferentes substratos $\mathrm{e}$ sombreamentos voltados para a emergência de Schizolobium amazonicum Huber ex Ducke, foi observado tanto em condições de sombreamento como a pleno sol, que a maioria dos substratos onde em sua composição havia pó de serra fresco ou curtido, foram desfavoráveis ao desenvolvimento do sistema radicular das mudas (GONDIN et al., 2015).

Sousa et al. (2015) em trabalho com diferentes substratos, verificaram valores superiores para comprimento de raízes nas plantas cultivadas no substrato esterco bovino + Forth condicionador. Os mesmos autores descrevem que esses resultados podem ser por causa da presença da matéria orgânica em maior quantidade no esterco 
bovino e no Forth condicionador, favorecendo assim as características físicas do solo, retenção de água e aeração. Gazola et al. (2013) em estudo com pepino, foi encontrado pelos autores maiores comprimento de raízes no substrato Forth condicionador.

Tabela 1. Analise química dos substratos $(\mathrm{g} / \mathrm{kg})$

\begin{tabular}{lccccc}
\hline & $\mathrm{P}$ & $\mathrm{K}$ & $\mathrm{Na}$ & $\mathrm{Ca}$ & $\mathrm{Mg}$ \\
\hline T1 - Esterco caprino & 3,85 & 32,80 & 28,70 & 14,51 & 5,35 \\
T2 - Esterco caprino + pó de serra & 1,71 & 12,80 & 9,60 & 6,17 & 2,23 \\
T3 - Esterco caprino + substrato comercial & 2,88 & 16,00 & 12,80 & 10,50 & 5,50 \\
T4 - Esterco caprino + areia lavada & 0,76 & 0,70 & 0,60 & 2,63 & 0,58 \\
\hline
\end{tabular}

Tabela 2. Índice de velocidade de emergência (IVE) do feijão Lablab purpureus em diferentes substratos.

\begin{tabular}{lc}
\hline Tratamentos & IVE \\
\hline T1 - Esterco caprino & $0,89 \mathrm{~b}$ \\
T2 - Esterco caprino + pó de serra & $1,40 \mathrm{a}$ \\
T3 - Esterco caprino + substrato comercial & $1,46 \mathrm{a}$ \\
T4 - Esterco caprino + areia & $0,62 \mathrm{~b}$ \\
\hline
\end{tabular}

Médias seguidas de mesma letra na coluna não diferem estatisticamente entre si, pelo teste de Tukey a 5\%.

Figura 1: Desenvolvimento do feijão em diferentes substratos

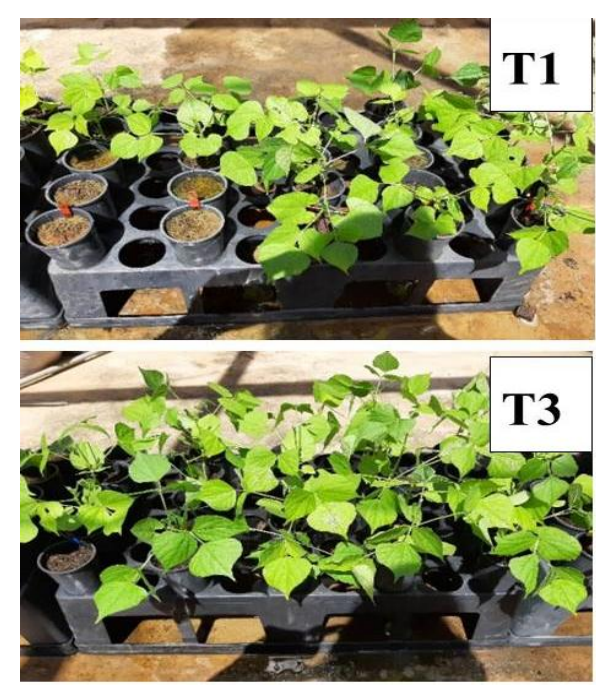

Fonte: Autoria própria

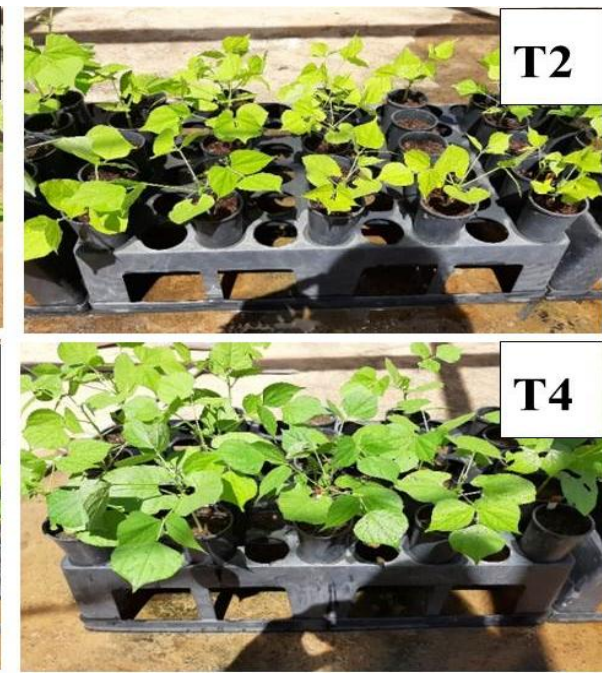

\section{T2}

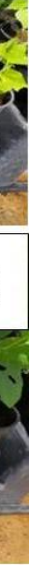
(1) 
encontrou que a dosagem de $20 \%$ desse composto possibilitou maior desenvolvimento das mudas. É ressaltado por Gondin et al. (2015) que o pó de serra tanto fresco quanto curtido, apesar dos resultados positivos para rápida emergência das plântulas e crescimento do sistema radicular, deve ser usado com cautela para evitar o comprometimento da parte aérea das mudas.

Com relação aos números de folhas os tratamentos esterco caprino e esterco caprino + substrato comercial tiveram os melhores resultados em comparação com os demais tratamentos (Tabela 3).

Em pesquisa realizada com feijão bravo-doCeará, para o número de folhas, o tratamento com $50 \%$ de composto orgânico obteve maior média em relação aos demais tratamentos (TELES et al., 2012). Medeiros et al. (2008), verificaram que o substrato com composto orgânico na sua formação ocasionou para o número de folhas e comprimento de raiz, valores superiores aos demais substratos. Em estudo realizado com diferentes substratos e em diferentes recipientes na formação de mudas de mamoeiro, na relação número de folhas, foi observado maiores médias com os substratos Plantimax®, esterco de curral + carvão vegetal + solo e areia e vermicomposto + carvão vegetal + solo e areia para bandejas e tubetes (MENDONÇA et al., 2003).

Em trabalho com diferentes substratos, esterco bovino, caprino e comercial, os dados para o número de folhas, teve a maior média quando se utilizou a proporção de $31,37 \%$ de matéria orgânica (PEREIRA et al., 2015). Araújo Neto et al. (2014), observaram que o valor médio do número de folhas nas plantas cultivadas no esterco de ovino foi maior quando comparados com esterco bovino. Os mesmos autores atribuíram essa superioridade de número de folhas a maior concentração de nutrientes contidos no esterco ovino.

Os tratamentos T1, T3 e T4 apresentaram os melhores resultados de diâmetro de colmo, não diferenciaram significativamente entre si. $O$ tratamento T2 obteve a menor média de todos os tratamentos (Tabela 3).
Tanto T1 e T3 apresentaram os maiores valores de potássio, que segundo Valeri e Corradini (2005), afirmam que o potássio, além de regular a abertura estomática, promove o engrossamento do caule das mudas. Porém, o tratamento T4 apresentou o menor valor para o elemento potássio. Em estudo realizado avaliando diferentes substratos para a produção de mudas de $S$. virgata, a associação potássio e diâmetro do colmo não foi evidente, onde as maiores médias de diâmetro do caule das mudas foram alcançadas nos tratamentos com menores teores de potássio (DELARMELINA et al., 2014).

Rontani et al. (2017) estudando o crescimento inicial de guapuruvu, constataram que havia diferenças no diâmetro do caule em função do substrato utilizado. Lima et al. (2017) estudando produção de mudas de aroeira-do-sertão (Myracrodruon urundeuva Allemão) em resíduos orgânicos, obteve maiores médias de diâmetro de caule para esterco ovino em relação aos valores encontrados para o esterco bovino.

A massa fresca dos tratamentos T3 e T4 apresentaram os melhores resultados. Já 0 tratamento T2 apresentou valores superiores ao tratamento T1 (Tabela 3).

Em estudo realizado com diferentes substratos e em diferentes recipientes na formação de mudas de mamoeiro, quanto à matéria fresca e seca das raízes, as combinações saco de polietileno e os substratos esterco de curral + carvão vegetal + solo e areia ou Plantimax® proporcionaram maiores médias de matéria fresca e seca (Mendonça et al., 2003). Em pesquisa avaliando diferentes substratos e temperaturas com sementes Foeniculum vulgare, o substrato areia não obteve valores significativos para massa fresca (RANZINI et al., 2016).

A massa seca do tratamento T4 constatou valores significativamente maiores que os demais tratamentos. O tratamento T3 obteve valor superior ao tratamento T2. E o T2 teve valores maiores que o tratamento T1 (Tabela 3).

Tabela 3. Altura da planta (ALT), Comprimento da raiz (CR), Numero de folhas (NF), Diâmetro do colmo (DC), Massa fresca (MF), Massa seca (MS), de Lablab purpureus.

\begin{tabular}{lllllll}
\hline & ALT $(\mathrm{cm})$ & $\mathrm{CR}(\mathrm{cm})$ & $\mathrm{NF}$ & $\mathrm{DC}(\mathrm{mm})$ & $\mathrm{MF}(\mathrm{g})$ & $\mathrm{MS}(\mathrm{g})$ \\
\hline T1 & $19,84 \mathrm{~b}$ & $17,92 \mathrm{~b}$ & $14,04^{\mathrm{a}}$ & $3,06 \mathrm{a}$ & $4,11 \mathrm{c}$ & $0,70 \mathrm{~d}$ \\
T2 & $14,61 \mathrm{c}$ & $18,43 \mathrm{~b}$ & $11,12 \mathrm{~b}$ & $2,55 \mathrm{~b}$ & $5,48 \mathrm{~b}$ & $1,14 \mathrm{c}$ \\
T3 & $22,83 \mathrm{a}$ & $20,54^{\mathrm{a}}$ & $13,80^{\mathrm{a}}$ & $2,90 \mathrm{a}$ & $9,36^{\mathrm{a}}$ & $2,17 \mathrm{~b}$ \\
T4 & $20,61 \mathrm{~b}$ & $18,08 \mathrm{~b}$ & $11,28 \mathrm{~b}$ & $2,91 \mathrm{a}$ & $10,08^{\mathrm{a}}$ & $2,62 \mathrm{a}$ \\
\hline
\end{tabular}

Médias seguidas de mesma letra na coluna não diferem estatisticamente entre si, pelo teste de Tukey a $5 \%$.

O tratamento com areia apresentou maior volume de raízes que os demais tratamentos, isso pode estar relacionado a características físicas do material e também da retenção de umidade do substrato. Em pesquisa com diferentes substratos no desenvolvimento de mudas de Areca-de-lucuba, para as variáveis massa seca da parte aérea e do sistema radicular observou-se diferença significativa entre os tratamentos, onde 0 Plantimax $\AA$ apresentou menor valor (BARDIVIESSO et al., 2011). Alves et al. (2008) analisando diferentes substratos, observaram que a massa seca das 
raízes de plântulas de mulungu apresentaram menores valores com os substratos Bioplant ${ }^{\circledR}$ e Plugmix ${ }^{\circledR}$, não recomendado 0 uso desses substratos na produção de mudas dessa espécie.

Com resultados diferentes Dutra et al. (2012) relata que para as variáveis matéria seca da raiz e da parte aérea de mudas de Canafístula os substratos Bioplant ${ }^{\circledR}$ e $75 \%$ Bioplant $\AA \quad+25 \%$ Bagaço de cana apresentaram as maiores médias, sendo a mistura nessa proporção uma prática de baixo custo para o produtor; e segundo o autor, esses valores de matéria seca pode ser atribuídos às características físicas de porosidade e capacidade de retenção de água. Em trabalho com diferentes substratos, esterco bovino, caprino e comercial, houve maior acúmulo de massa seca com proporções em torno dos $30 \%$ de material orgânico (PEREIRA et al., 2015). Coelho et al. (2010) em pesquisa realizada com Caesalpinia ferrea utilizando escarificação mecânica em diferentes regiões da semente para superação de dormência, alcançaram maiores valores de produção de massa seca do sistema radicular com a técnica de escarificação mecânica com lixa na extremidade oposta ao hilo.

Os baixos valores de massa fresca e massa seca das mudas podem estar relacionados ao excesso de nutrientes presentes no esterco caprino, que quando utilizado puro pode dificultar a absorção dos nutrientes pelas mudas. $\mathrm{E}$ quando misturado com outro material ouve a diminuição dos nutrientes presentes no tratamento. Segundo Cruz et al. (2006) e Pereira et al. (2015), a presença em excesso de sódio no substrato tem como efeito negativo a redução no crescimento e desenvolvimento dos vegetais. Esses íons causam mudanças na capacidade das plantas em absorver, transportar e utilizar alguns nutrientes, e estão também relacionados ao efeito osmótico, induzindo a planta ao estresse hídrico, e ao efeito tóxico direto sobre os sistemas enzimáticos e membranas.

\section{Conclusões}

Para tanto, os dados analisados mostraram que para o crescimento emergencial do feijoeiro o tratamento de esterco caprino associado ao substrato comercial mostrou-se mais eficiente, obtendo assim um melhor desempenho nas mudas de feijão Lablab purpureus, podendo ser utilizado futuramente para o plantio de novas plantas.

\section{Referencias}

ALVES, J. D. N.; MOREIRA, W. K. O.; OLIVEIRA, S. S.; LEAO, F. A. N.; OKUMURA, R. S. Taxa e índice de velocidade de emergência de parica em diferentes substratos e frequência de irrigação. Enciclopédia Biosfera, Centro Cientifico Conhecer - Goiania, v.11, n. 21 ; p. 2015.

ALVES, E. U.; ANDRADE, L. A. DE; BARROS, H. H. DE A.; GONÇALVES, E. P.; ALVES, A. U.; GONÇALVES, G. S.; OLIVEIRA, L. S. B. DE; CARDOSO, E. DE A. Substratos para testes de emergência de plântulas e vigor de sementes de Erythrina velutina Willd., Fabaceae. Semina: Ciências Agrárias, Londrina, v. 29, n. 1, p. 69-82, jan./mar. 2008.

ARAÚJO, A. P. de; SOBRINHO, S. de P. Germinação e produção de mudas de tamboril (Enterolobium contortisiliquum (vell.) morong) em diferentes substratos. Revista Árvore, Viçosa-MG, v.35, n.3, Edição Especial, p.581-588, 2011.

ARAÚJO NETO, R. A.; ARAÚJO FILHO, J. T.; SILVA, F. J.; ROCHA, A. E. Q.; FARIAS, J. J. A. Desenvolvimento do sorgo (Sorghum bicolor L. moench) forrageiro submetido a diferentes tipos e doses de adubação orgânica. Revista Ciência Agrícola, Rio Largo, v.12, n.1, p.31-40, 2014.

ARAÚJO, W. B. M.;ALENCAR, R. A.; MENDONÇA, V.; MEDEIROS, E. V.; ANDRADE, R. C.; ARAÚJO, R. R. Esterco caprino na composição de substratos para formação de mudas de mamoeiro. Ciência e Agrotecnologia, Lavras, v.34, n.1, p.68-73, 2010.

BARDIVIESSO, D. M.; MARUYAMA, W. I.; REIS, L. L. DOS; MODESTO, J. H.; REZENDE, W. E. Diferentes substratos e recipientes na produção de mudas de guabiroba (Campomanesia pubescens o.berg). Revista Científica Eletrônica de Agronomia, Garça, v.18, n.1, p. 52-59, jun, 2011.

BOCCHESE, R. A.; OLIVEIRA, A. K. M. DE; FERNANDES, A. M. V. M.; LAURA, V. A. Efeito de diferentes tipos de solos na germinação de Tabebuia heptaphylla, em casa telada. Cerne, Lavras, v. 14, n. 1, p. 62-67, jan./mar. 2008.

COELHO, M. F. B.; MAIA, S. S. S.; OLIVEIRA, A. K. DE; DIÓGENES, F. E. P. Superação da dormência tegumentar em sementes de Caesalpinia ferrea Martex Tul. Revista Brasileira de Ciências Agrárias, Recife, v. 5, n. 1, p. 74-79, 2010.

CRUZ, J. L.; PELACANI, C. R.; COELHO, E. F.; CALDAS, R. C.; ALMEIDA, A. Q.; QUEIROZ, J. R. Influência da salinidade sobre o crescimento, absorção e distribuição de sódio, cloro e macronutrientes em plântulas de maracujazeiro-amarelo. Bragantia, Campinas, v.65, p.275284, 2006.

DUTRA, R. T.; MASSAD, D. M.; SARMENTO, Q. F. M.; OLIVEIRA, J. C. Emergência e crescimento inicial da canafístula em diferentes substratos e métodos de superação de dormência. Revista Caatinga, Mossoró, v. 25, n. 2, p. 65-71, mar.-jun., 2012.

DAN, L. G. M.; DAN, H. A.; BARROSO, A. L. L.; BRACCINI, A. L. Qualidade fisiológica de sementes de soja tratadas com inseticidas sob efeito do armazenamento. Revista Brasileira de Sementes, Londrina, v.32, n.2, p.131-139. 2010.

DELARMELINA, W. M.; CALDEIRA, M. V. W.; FARIA, J. C. T.; GONÇALVES, E. O.; ROCHA, F. L. F. Diferentes substratos na produção de mudas de Sesbania virgata (Cav.) Pers. Floresta e Ambiente, v. 21, n. 2, p. 224-233, 2014.

DORNELLES, A. L. C.; LIMA, A. R.; CAMPOS, V. C. Avaliação do potencial de armazenamento de sementes de Annona crassiflora MART, Annona muricata L.e 
Annona squamosa L. In: CONGRESSO BRASILEIRO DE FRUTICULTURA, 17., 2002, Belém. Anais...Fortaleza: SBF, 2002. CD ROM.ENGLE, L. M.; ALTOVERIS, N. C. Collection, Conservation and Utilization of Indigenous Vegetables. Asian Vegetable Research and Development Centre (AVRDC), Shanhua, p. 142, 2000.

FREIRE, A. L. O.; RAMOS, F. R.; GOMES, A. D. V.; SANTOS, A. S.; ARRIEL, E. F. Crescimento de mudas de craibeira (Tabebuia aurea (Manso) Benth. \& Hook) em diferentes substratos. Agropecuária Científica no Semiárido, v.11, n.03, p.38-45, 2015.

FERMINO, M.H.; KAMPF, A.N. Uso do solo bom Jesus com condicionadores orgânicos como alternativa de substrato para plantas. Pesquisa Agropecuária Gaúcha, Porto Alegre, v.9, n.1/2, p.33-41, 2003.

FRANCO, L. H.; PETERS, M; SCHU1TZE-KRAFL, R. Lablab purpureus una leguminosa multipropósito. Centro Internacional de Agricultura Tropical Proyecto de Forrajes Tropicales. 2006.

GAZOLA, R. N.; CASTILHO, R. M. M.; DINALLI, R. P.; CELESTRINO, T. S.; MÓDENA, C. M. Germinação e crescimento inicial de plântulas de pepino em substratos comerciais. Tecnologia \& Ciência Agropecuária, João Pessoa, v.7, n.3, p.25-30, 2013.

GONDIN, J. C.; SILVA, J. B. DA; ALVES, C. Z.; DUTRA, A. S.; JUNIOR, L. E. Emergência de plântulas de Schizolobium amazonicum Huber ex Ducke (CAESALPINACEAE) em diferentes substratos e sombreamento. Revista Ciência Agronômica, v. 46, n. 2, p. 329-338, abr-jun, 2015.

LIMA, J.F.; SILVA, M.P.L.; TELES, S.; SILVA, F.; MARTINS, G.N. Avaliação de diferentes substratos na qualidade fisiológica de sementes de melão de caroá (Sicana odorifera (Vell.) Naudim). Revista Brasileira de Plantas Medicinais, Botucatu, v.12, n.2, p.163-167, 2010.

LIMA, L. K. S; MOURA, M. C. F; SANTOS, C. C; NASCIMENTO, K. P.C; DUTRA, A. S. Produção de mudas de aroeira-do-sertão (Myracrodruon urundeuva Allemão) em resíduos. Revista Ceres, Viçosa, v. 64, n.1, p. 001- 011, jan/fev, 2017.

LUZ, F. N.; SANTOS, P. R. R.; DOURADO, D. P.; FERREIRA, C. C. B.; CONCEIÇÃO, W. S. S.; MURAISH, C. T. Uso de diferentes doses de serragem como fonte de substrato para a produção de mudas de quiabo. XXXIV congresso brasileiro de ciência do solo, 2013.

MALAVOLTA, E. Potássio é uma realidade - o potássio é essencial para todas as plantas. Ciência e Agrotecnologia, Lavras, v.25, n.3, p.542-549, 1996.

MENDONÇA, V.; NETO, S. E. DE A.; RAMOS, J. D.; PIO, R.; GONTIJO, T. C. A. Diferentes substratos e recipientes na formação de mudas de mamoeiro 'sunrise solo'. Revista Brasileira de Fruticultura, Jaboticabal - SP, v. 25, n. 1, p. 127-130, Abril 2003.

MEDEIROS, D.C.; FREITAS, K.C.S.; VERAS, F.S.; ANJOS, R.S.B.; BORGES, R.D.; CAVALCANTE NETO, J.G.; NUNES, G.H.S.; FERREIRA, H.A. Qualidade de mudas de alface em função de substratos com e sem biofertilizante. Horticultura Brasileira, v. 26, n. 2, 186-189, 2008.

MELO, R. F.; ANJOS, J. B.; SILVA, A. F.; PEREIRA, L. A.; CRUZ, L. C. Influência de doses de esterco de caprino no desenvolvimento de mandioca de mesa (Manihot esculenta Crantz) em barragem subterrânea. XXXV CONGRESSO BRASILEIRO DE CIÊNCIA DO SOLO, Anais..., Natal, 2015.

MURPHY, A.M.; COLUCCI, P. E. A tropical forage solution to poor quality ruminant diets: A review of Lablab purpureus.

1999. http://www.fao.org/ag/aga/agaP/Frg/FEEDback//rrd//rrd11/ 2/colu112.htm._Acesso em: 13/01/2020.

MORRIS, J. B. Morphological and reproductive characterization in hyacinth bean, Lablab purpureus (L.) Sweet germplasm with clinically proven nutraceutical and pharmaceutical traits for use as a medicinal food. J Diet Suppl 6(3):263-279, 2009.

OLIVEIRA, F. T.; HAFLE, O. M.; MENDONÇA, V.; MOREIRA, J. N.; PEREIRA JUNIOR, E. B.; ROLIM, H. O. Respostas de porta-enxertos de goiabeira sob diferentes fontes e proporções de materiais orgânicos. Comunicata Scientiae, Bom Jesus, v.6, n. 1, p.17-25, 2015.

PEREIRA, E. C.; CÂMARA, F. M. DE M., MENDONÇA, V.; COSTA, J. M.; CARNEIRO, J. V.; SILVA, R. M. Fontes, proporções de materiais orgânicos e doses de fósforo na produção de mudas de pinha. Agropecuária Científica no Semiárido, v.11, n.03, p.84-96, 2015.

PENGELLY, B. C.; LISSON, S. N. Strategies for Using Improved Forages to Enhance Production in Bali Cattle. In: K. Entwistle and D. R. Lindsay, Eds., Proceedings of a Workshop Australian Centre for International Agricultural Research (ACIAR), Bali, 4-7 February, p. 29-33, 2002.

PITON, L. P. Produção de mudas de Piper aduncum I. em diferentes condições de luz, substratos e procedências, 2016. 81f. Tese de (mestrado em Agricultura Tropical) Faculdade de Agronomia e Zootecnia da Universidade Federal de Mato Grosso, Cuiabá, 2016.

PEREIRA D.L.; OLIVEIRA RH; SOUZA EGF; FERRAZ APF; COELHO JUNIOR LF. BARROS JUNIOR AP 2012. Uso de fontes orgânicas como substrato na produção de mudas de melão. Hortic. Bras., v. 30, n. 2, Julho 2012.

RANZANI, R.E.; LUZ, P.B.; MAROSTEGA, T.N.; SOBRINHO, S. P. Efeitos de diferentes substratos e temperaturas na germinação de sementes de Foeniculum vulgare. Revista Brasileira de Plantas Medicinais, Campinas, v.18, n.1, supl. I, p.363-366, 2016.

RONTANI, F. A.; PIRES, J. O.; DELLARMELIN, S.; DIAS, T. R.; CANTARELLI, E. B. Desenvolvimento inicial de mudas de Schizolobium parahyba (VELL.) S. F. BLAKE produzidas em diferentes substratos. Enciclopédia Biosfera, Centro Cientifico Conhecer - Goiânia, v.14 n.25; p. 2017

SILVA, T. O.; MENEZES, R. S. C.; TIESSEN, H.; SAMPAIO, E. V. S. B.; SALCEDO, I. H.; SILVEIRA, L. M. Adubação orgânica da batata com esterco e, ou, Crotalaria juncea. I - produtividade vegetal e estoque de 
nutrientes no solo em longo prazo. Revista Brasileira de Ciência do Solo, v. 31, n. 1, p. 39-49, 2007.

SCALON, S. P. Q.; MUSSURY, R. M.; ALMEIDA, K. A.; RIGONI, M. R. Efeito do álcool e substrato na germinação de sementes de sibipiruna (Caesalpinia pelthophoroides Benth.) colhidas no chão e retiradas da vagem. Ciência e Agrotecnologia, Lavras, v. 27, n. 2, p. 389-392, 2003.

SANTOS, E. M.; CAMPOS, R. A. S. Germinação de sementes de ipê-amarelo Tabebuia ochracea (Chamb.) Standl. (BIGNONIACEAE) em diferentes substratos. In: JORNADA CIENTÍFICA DA UNEMAT, 2., 2009, Barra do Bugres. Anais... Barra do Bugres: UNEMAT, 2009.

SILVA, R. P.; PEIXOTO, J. R.; JUNQUEIRA, N. T. V. Influência de diversos substratos no desenvolvimento de mudas de maracujazeiro azedo (Passiflora edulis Sims $\mathrm{f}$. flavicarpa DEG). Revista Brasileira de Fruticultura, Jaboticabal, v. 23, n. 2, p. 377-381, 2001.

SMIDERLE, O. S.; MINAMI, K. Emergência e vigor de plântulas de goiabeira em diferentes substratos. Revista Científica Rural, Bagé, v. 6, n. 1, p. 38-45, 2001.

SCHMITZ, J. A. K.; SOUZA, P. V. D.; KAMP, A. N. Propriedades químicas e físicas de substratos de origem mineral e orgânica para o cultivo de mudas em recipientes. Ciência Rural, v.32, n.6, p.937-944, 2002.
SANTOS, C. B.; LONGHI, S. J.; HOPPE, J. M.; MOSCOVICH, F. A. Efeito do volume de tubetes e tipos de substratos na qualidade de mudas de Cryptomeria japonica (L. F.) D. Don. Ciência Florestal, Santa Maria 10(2): 1-15. 2000.

SOUSA, G. C.; RIBEIRO, A. A.; MENEZES, A. S.; MOREIRA, F. J. C.; CUNHA, C. S. M. Emergência e crescimento inicial de sorgo (Sorghum bicolor L.) em diferentes substratos. Agropecuária Científica no Semiárido, v.11, n.4, p.63-71, 2015.

TELES, V.O.; SILVA, W.C.; SILVA, R.D.; CAMARA, F.T. Germinação e desenvolvimento do feijão bravo-do-ceará (Carnavalia brasiliensis) em diferentes proporções de composto orgânico. Caderno de cultura e ciência, ano VII, v.11, n.1, dez, 2012.

VALE, L. S. do; COSTA, J. V. T.; ANUNCIAÇÃO FILHO, C. J.; LIMA, R. L. S. de. Efeito de diferentes misturas de substrato e tamanho de recipientes na produção de mudas mamoeiro. In: BARBOSA, J. G.; MARTINEZ, H. E. P.; PEDROSA, M. W. Nutrição e adubação de plantas cultivadas em substrato. Viçosa: UFV, p. 385, 2004.

VALERI, S. V.; CORRADINI, L. Fertilização em viveiros para a produção de mudas de Eucalyptus e Pinus. In: GONÇALVES, J. L. M.; BENEDETTI, V. (Eds.). Nutrição e fertilização florestal. Piracicaba: Instituto de Pesquisas e Estudos Florestais; p. 167-190, 2005. 